\title{
Which bridge to cross, which mountain to climb - Supramolecular Photocatalysis Outpacing Conventional Catalysis
}

Linda Zedler ${ }^{a, b, \S}$, Pascal Wintergerst ${ }^{c, \S}$, Alexander K. Mengelec, Carolin Müller ${ }^{a, b}$, Chunyu Li ${ }^{a}$, Benjamin Dietzek ${ }^{\mathrm{a}, \mathrm{b}, \mathrm{d}, *}$, Sven Rau ${ }^{\mathrm{c}, *}$

anstitute of Physical Chemistry, Friedrich Schiller University Jena, Helmholtzweg 4, 07743 Jena, Germany

beibniz Institute of Photonic Technology Jena, Department Functional Interfaces, Albert-EinsteinStraße 9, 07745 Jena, Germany

'Institute of Inorganic Chemistry I, Materials and Catalysis, Ulm University, Albert-Einstein-Allee 11, 89081 Ulm, Germany

${ }^{\mathrm{d}}$ Center for Energy and Environmental Chemistry Jena (CEEC Jena), Philosophenweg 7a, 07743 Jena

*sven.rau@uni-ulm.de and benjamin.dietzek@uni-jena.de

$\S$ These authors contributed equally.

\section{Abstract}

Unequivocal assignment of rate limiting steps in supramolecular photocatalysts is of utmost importance to rationally optimize photocatalytic activity. By spectroscopic and catalytic analysis of a series of three structurally similar $\left[(\mathrm{tbbpy}){ }_{2} \mathrm{Ru}-\mathrm{BL}-\mathrm{Rh}\left(\mathrm{Cp} \mathrm{p}^{*}\right) \mathrm{Cl}\right]^{3+}$ photocatalysts just differing in the central part (alkynyl, triazole or phenazine) of the bridging ligand $(\mathrm{BL})$ we were able to derive design strategies for improved photocatalytic activity of this class of compounds (tbbpy $=4,4$ '-tert-butyl2,2'-bipyridine, $\mathrm{Cp}^{*}=$ pentamethylcyclopentadienyl). Most importantly, not the rate of the transfer of the first electron towards the $\mathrm{Rh}^{\text {III }}$ center but rather the rate at which a two-fold reduced $\mathrm{Rh}^{\prime}$ species is generated can directly be correlated with the observed photocatalytic formation of NADH from $\mathrm{NAD}^{+}$. Interestingly, the complex which exhibited the fastest intramolecular electron transfer kinetics for the first electron is not the one that allowed the fastest photocatalysis. With the photocatalytically most efficient alkynyl linked system, it was even possible to overcome the rate of thermal NADH formation. Moreover, for this photocatalyst loss of the alkynyl functionality under photocatalytic conditions was identified as an important deactivation pathway. 


\section{Introduction}

One of the biggest challenges of the century is to turn the currently unsustainable energy production upside down. ${ }^{1}$ Therefore, renewables such as wind or solar power have to meet a large share of the energy needs of economy and private households in the near future. A promising approach to deal with the inherent intermittencies of renewable energies is to store them in chemical bonds. ${ }^{2}$ Photocatalytic water splitting using molecular components could represent one of many viable solutions to this goal. ${ }^{2,3}$ In this context, di- or oligonuclear supramolecular photocatalysts consisting of a chromophoric moiety and a catalytic center connected by an electron transporting bridging ligand might represent a very promising approach. ${ }^{4}$

Much work has been performed to understand the molecular prerequisites for optimized photocatalytic output using supramolecular photocatalysts. ${ }^{5,6}$ As the organic bridging ligand is at the heart of such oligonuclear photocatalysts, it is essential to fine tune this component in order to allow for multiple unidirectional electron transfers between chromophore and catalyst. ${ }^{7}$ Thus, a plethora of synthetic optimization work, supported by (time-resolved) spectroscopy has been done to understand the correlation of structural changes of the bridging ligand and photocatalytic output measured in terms of turnover number (TON) or turnover frequency (TOF). ${ }^{6,8-10}$ Examples for such rational synthetic approaches, are the introduction of bromine moieties in the (paradigm) tpphz bridging ligand by Karnahl et al., which led to a decrease in electron transfer rate and in turn lowered catalytic activity. ${ }^{9}$ Another approach was taken by Ishitani et al. comparing the orientation of an asymmetric bridging ligand. While one orientation led to electron density being mainly localized on the photosensitizer, thereby inhibiting catalytic turnover, the other orientation, while enabling efficient electron transfer, led to a decreased reducing power of the catalyst. ${ }^{11}$

However, the complexity of the investigated light-driven multielectronic processes, quite often renders the assignment of the bottleneck in photocatalysis difficult, i.e. identifying the one most 
critical parameter to lift limitations in the photocatalytic activity is - generally speaking - an unsolved problem. In many cases it is not clear whether e.g. the sum of various visible light-driven electron transfer processes to activate the catalyst or turnover at the photochemically activated catalyst represented the bottleneck. This is because the light-independent turnover rate at the catalytically active center has so far only been investigated for water oxidation catalysts. ${ }^{12,13}$

In order to unequivocally clarify for a model series of supramolecular photocatalysts whether initial photochemical reduction of the catalyst or subsequent turnover at the catalytically active species represents the rate-limiting step, it is important to select systems where these two processes are principally decoupled from each other. A very promising example are $\left[(\mathrm{NN}) \mathrm{Rh}\left(\mathrm{Cp}{ }^{*}\right) \mathrm{Cl}\right]$-based catalysts ( $\mathrm{NN}=\alpha$-diimine ligand, $\mathrm{Cp}^{*}=$ pentamethylcyclopentadienyl) which are well understood in terms of their redox chemistry ${ }^{14-16}$ and the mechanism of photochemical or thermal selective nicotinamide reduction. ${ }^{17-19}$ Hence, such $[(\mathrm{NN}) \mathrm{Rh}(\mathrm{Cp} *) \mathrm{Cl}]$-based catalysts have found widespread applications in the area of cofactor recycling for enzymatic reactions. ${ }^{20-23}$ As shown in Figure 1, only after a two-fold photochemical reduction of the $\mathrm{Rh}^{\text {"II }}$ center, the light-independent hydride transfer onto the nicotinamide derivative takes place, initiated by proton addition to the photochemically generated $\mathrm{Rh}^{\prime}$ species. ${ }^{16}$

Furthermore, these $\left[(\mathrm{NN}) \mathrm{Rh}\left(\mathrm{Cp}^{*}\right) \mathrm{Cl}\right]$-based systems feature the possibility that both photochemical formation of $\mathrm{Rh}^{124}$ and catalytic turnover ${ }^{18,25}$ can be evaluated independently from each other (see Figure 1). However, the reactivity of the $\left[(\mathrm{NN}) \mathrm{Rh}\left(\mathrm{Cp} \mathrm{p}^{*} \mathrm{Cl}\right]\right.$-based systems heavily depends on the direct coordination environment, i.e. the choice of the NN-ligand. ${ }^{15}$ Therefore, we designed two structurally related photocatalysts utilizing a modular composition of the bridging ligands. The two systems feature 1,10-phenanthroline (phen) coordination spheres on both the (tbbpy) ${ }_{2} \mathrm{Ru}$ chromophore moiety as well as the RhCp* catalyst subunit and are either linked via an alkyne or a triazole linker in the easy to modify 5-position (see Figure 1). ${ }^{26-28}$ In combination with the recently reported bridging ligand, a tpphz (tetrapyridophenazine) derivative, ${ }^{20,24}$ this allowed us to clearly assign for the first time photocatalytic reactivity changes in $\left[(\mathrm{NN})_{2} \mathrm{Ru}-\mathrm{BL}-\mathrm{Rh}\left(\mathrm{Cp}{ }^{*}\right) \mathrm{Cl}\right]^{3+}$ systems 


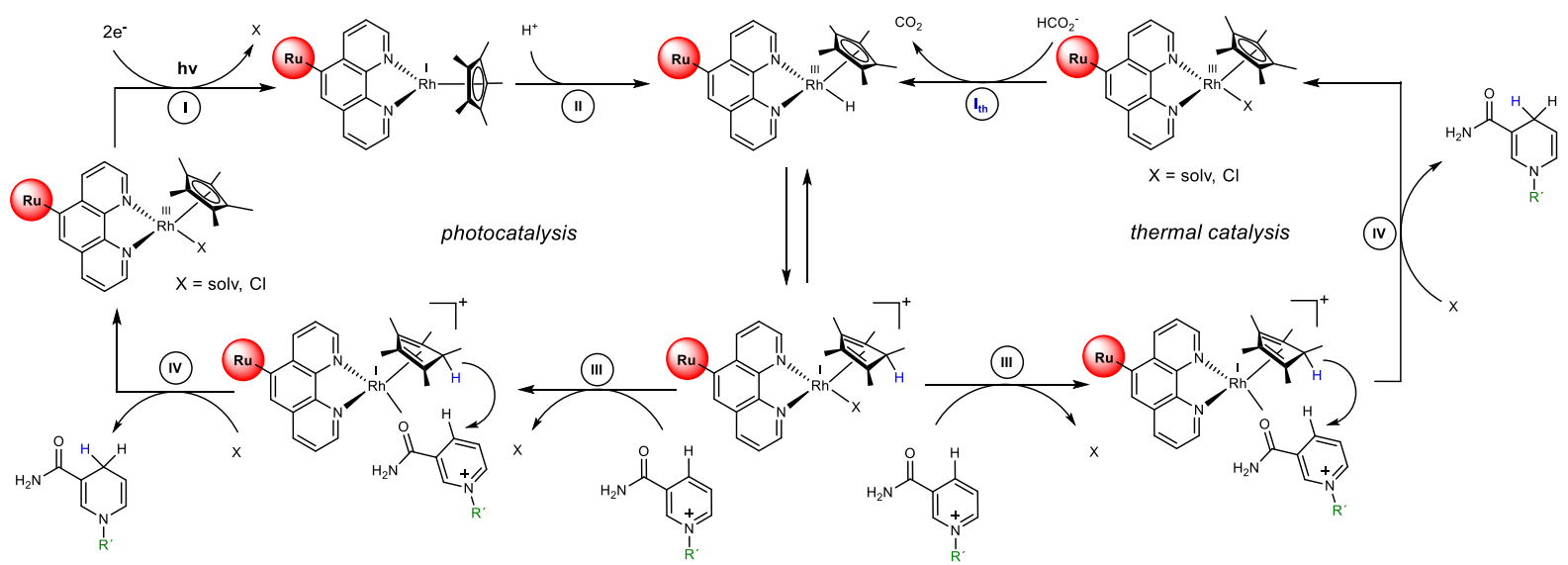

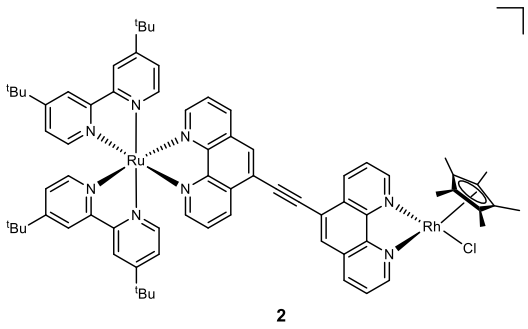

Ru

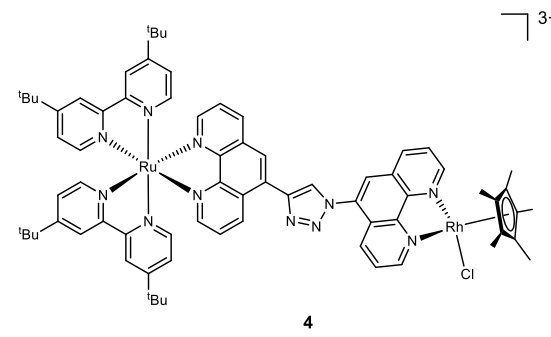

Ru-

Figure 1: Top: Depiction of the photocatalytic and thermal catalytic hydrogenation of nicotinic amides by rhodium catalysts. ${ }^{17-19}$ Photocatalysis: I) photocatalytic two electron reduction of Rh'II, II) oxidative addition of a proton under formation of a $R h^{\prime \prime \prime}\left(C p^{*}\right)$-hydride and equilibrium with isomeric $R h^{\prime}\left(C p^{*} H\right)$, III) coordination of the nicotinic amide and hydride transfer, IV) dissociation of the product and regeneration of the Rh'll starting state; Thermal catalysis: I $I_{\text {th }}$ ) coordination of formate and elimination of $\left.\mathrm{CO}_{2}, \mathrm{III}\right)$-IV) identical to the photocatalytic mechanism. Bottom: Molecular structure of the new photocatalysts 2 and 4. 


\section{Results}

\section{Synthesis.}

Both catalysts were prepared via chemistry on the complex. The starting complexes for catalysts $\mathbf{2}$ and 4 were (tbbpy) ${ }_{2} \mathrm{Ru}\left(5\right.$-bromo-1,10-phenanthroline) and (tbbpy) ${ }_{2} \mathrm{Ru}$ (5-ethinyl-1,10-phenanthroline) available from previous work, respectively. ${ }^{26,28}$ To access complex 1 we decided to construct the bridging ligand directly on the complex, although the ligand itself has been prepared before. ${ }^{29}$ The bromo derivative was subjected to Sonogashira reaction on the complex with 5-ethinyl-1,10phenanthroline in $55 \%$ yield. ${ }^{30}$ Complex 3 was accessible via click reaction using the ethinyl substituted complex as an alkyne and 5-azido-1,10-phenanthroline ${ }^{31}$ as azide in $63 \%$ yield. For introduction of the Rhodium center, complexes $\mathbf{1}$ and $\mathbf{3}$ were combined with $\left[\mathrm{Rh}\left(\mathrm{Cp}^{*}\right) \mathrm{Cl}_{2}\right]_{2}$ in methylene chloride to give nearly quantitative yields. All complexes were characterized via NMR spectroscopy and high-resolution mass spectrometry (Figures S1-8).

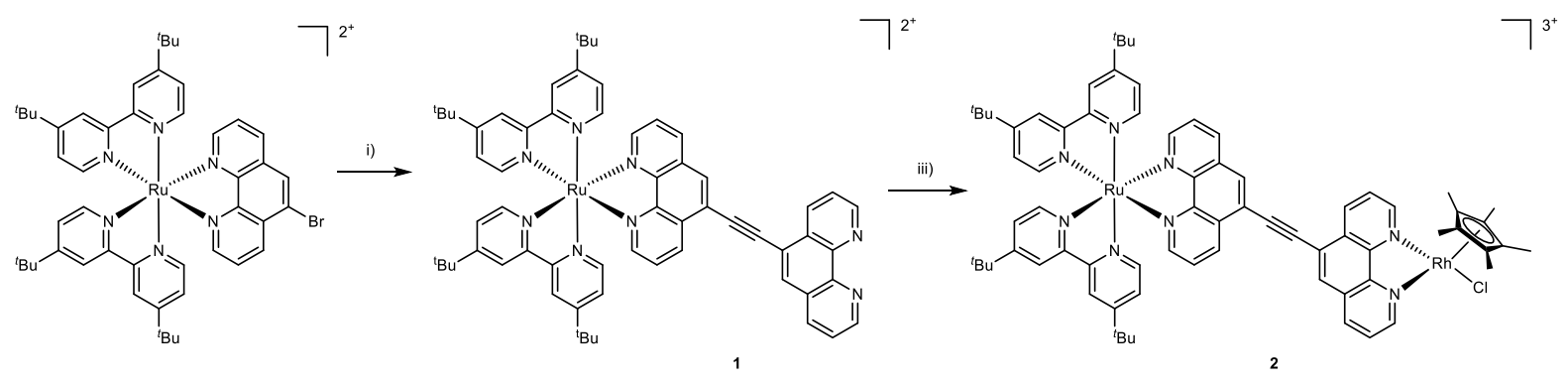

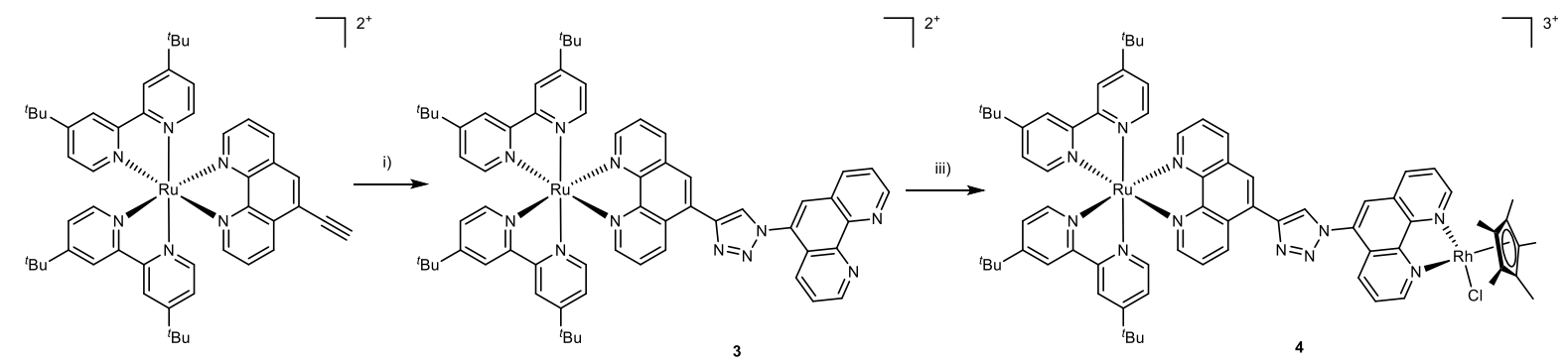

Figure 2: Synthesis of complexes 1, 2, 3 and 4 i) 1. 5-ethinyl-1,10-phenanthroline, THF, diisopropylamine, $\left(\mathrm{PPh}_{3}\right)_{4} \mathrm{Pd}^{0}, \mathrm{Cul}$, $60^{\circ} \mathrm{C}$, 24h 2. $\mathrm{KCN}$, dichloromethane $/ \mathrm{H}_{2} \mathrm{O}, \mathrm{rt}$, $1 \mathrm{~h}$ ii) 1. 5-azido-1,10-phenanthroline, CuSO $\mathrm{S}_{4}$, sodium ascorbate, $\mathrm{H}_{2} \mathrm{O}$ /dichloromethane, $r t$, 24h 2. $\mathrm{KCN}$, dichloromethane $/ \mathrm{H}_{2} \mathrm{O}, r t$, $1 \mathrm{~h} \mathrm{iii)}\left[\mathrm{Rh}\left(\mathrm{Cp}^{*}\right) \mathrm{Cl}_{2}\right]_{2}$, dichloromethane, $r t$, $24 \mathrm{~h}$. 


\section{Electrochemistry.}

The complexes dissolved in acetonitrile containing $n-\mathrm{Bu}_{4} \mathrm{NPF}_{6}$ were investigated by cyclic voltammetry. The Rh containing complexes show a reversible reduction at $-1.16(2)$ and $-1.13 \vee(4)$ vs. $\mathrm{Fc}^{+} / \mathrm{Fc}$ due to a two electron reduction of the $\mathrm{Rh}^{\prime \prime \prime} / \mathrm{Rh}^{\prime}$ couple. ${ }^{32,33}$ At more negative potentials, i.e. between -1.6 and $-2.2 \mathrm{~V} v$ s. $\mathrm{Fc}^{+} / \mathrm{Fc}$, 1-4 feature three reduction waves. At $-1.9 \mathrm{~V}$ and $-2.2 \mathrm{~V} v s . \mathrm{Fc}^{+} / \mathrm{Fc}$ the terminal bipyridine ligands become reduced, ${ }^{34,35}$ while the first reduction is localized on the bridging ligand. For the alkynyl complexes $\mathbf{1}$ and $\mathbf{2}$, this reduction $\left(-1.6 \mathrm{~V} v \mathrm{~s}\right.$. $\left.\mathrm{Fc}^{+} / \mathrm{Fc}\right)$ is shifted anodically by ca. $100 \mathrm{mV}$ compared to the triazole complexes 3 and $\mathbf{4}$ at $-1.7 \mathrm{~V}$ vs. Fc $/ \mathrm{Fc}$. All

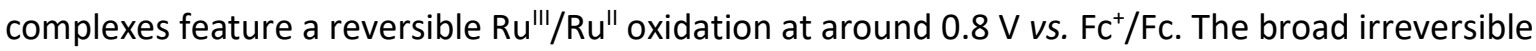
oxidation at ca. $0.6 \mathrm{~V}$ vs. $\mathrm{Fc}^{+} / \mathrm{Fc}$ stems from oxidation of the chloride anions. ${ }^{36,37}$

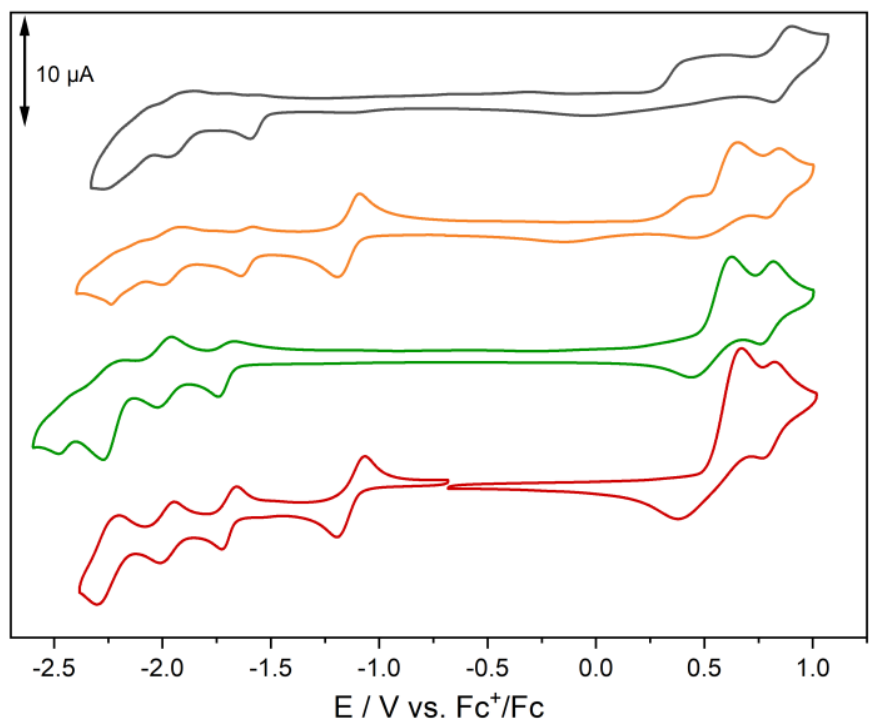

Figure 3: Cyclic voltammograms of separate $1 \mathrm{mM}$ acetonitrile solutions of $\mathbf{1}$ (blue), $\mathbf{2}$ (orange), $\mathbf{3}$ (green) and $\mathbf{4}$ (red) at room temperature with $n \mathrm{Bu}_{4} \mathrm{NPF}_{6}$ as supporting electrolyte $(0.1 \mathrm{M})$. $\mathrm{Ag} / \mathrm{AgCl}$ is used as reference electrode, $\mathrm{Pt}$ wire as the counter electrode and glassy carbon as the working electrode. All data referenced against $F c^{+} / F c$; scan rate $=100 \mathrm{mV} \mathrm{s}^{-1}$.

\section{Absorption and Emission.}

Figure 4 depicts the absorption and emission data recorded for the complexes under investigation. All four complexes feature very similar absorption properties characteristic for Ru polypyridine complexes. In acetonitrile, MLCT absorption bands with their maxima in the range of 452 to $454 \mathrm{~nm}$ are observed, regardless of the substituent in 5-position of the phenanthroline. Even the further 
expansion of the $\pi$-system in case of complexes $\mathbf{1}$ and $\mathbf{2}$ via the alkyne bond does not cause a significant change of the MLCT absorption band which is reminiscent of similar complexes with free alkyne substituents. ${ }^{28,38}$ For the alkyne based complexes $\mathbf{1}$ and 2, a broad absorption band at $345 \mathrm{~nm}$ is visible. Due to its absence in complexes $\mathbf{3}$ and $\mathbf{4}$, we can assign this to a ligand centered $\pi-\pi^{*}$ transition of the delocalized alkyne bridged phenanthrolines. ${ }^{29}$ Additionally, a typical strong absorption band at $280 \mathrm{~nm}$ is visible for all complexes caused by $\pi-\pi^{*}$ transitions on the bpy and phen ligands.

All complexes show phosphorescence centered at ca. $620 \mathrm{~nm}$ as typically observed for $\mathrm{Ru}(\mathrm{bpy})_{2}$ (phen)-derived complexes. ${ }^{39-42}$ Despite the very similar shape of the emission spectra, the emission intensity of $\mathbf{1}$ and $\mathbf{2}$ is reduced compared to their triazole-containing counterparts. Very intriguingly, comparing the emission intensities for the mononuclear ruthenium complexes with the corresponding heterodinuclear ruthenium-rhodium complexes, significant differences become visible. The emission intensity in dichloromethane of $\mathbf{1}$ drops by $82 \%$ in comparison to 2 upon introduction of the $\mathrm{Rh}^{\mathrm{III}}$ center. In contrast, the emission intensity in dichloromethane of $\mathbf{3}$ does only drop by $12 \%$ upon introduction of the $\mathrm{Rh}^{\mathrm{III}}$ center (4). Similar behavior of emission quenching upon introduction of a second metal center has been shown in the past. ${ }^{32,43-45}$ Significant loss of emission intensity has been associated with high likelihood of electron transfer to the catalytic center. ${ }^{46-51}$ This behavior is not mirrored by the lifetime of the emissive state where for the alkynyl bridged-systems slightly larger lifetimes (124 ns for 1 and 136 ns (slow lifetime component) for 2) compared to the triazole-containing complexes (114 ns for 3 and 113 ns for 4 ) could be observed. Together with the higher emission intensity observed for $\mathbf{3}$ and $\mathbf{4}$ this indicates that the radiative rate in the alkynyl bridged-systems is lower than in the triazole-linked complexes. We ascribe this finding to a more delocalized long-lived ${ }^{3} \mathrm{MLCT}$ state in the alkynyl bridged systems. Such electronic delocalization lowers the LUMO and causes the minute bathochromic shift of the emission spectra of $\mathbf{1}$ and $\mathbf{2}$ when compared to $\mathbf{3}$ and $\mathbf{4}$. However, the electronic delocalization also partially removes electronic density from the nitrogens coordinating the $\mathrm{Ru}$ "III ion and hence reduces the oscillator strength of the 
${ }^{3} \mathrm{MLCT} \rightarrow \mathrm{S}_{0}$ transition. The bi-exponential emission decay for the binuclear alkynyl complex $\mathbf{2}$ with a fast decay time of $18 \mathrm{~ns}$ is indicative of a second decay channel for the emissive state, which we attribute to electron transfer to the Rh sphere. The fact that such fast decay component is not observed in $\mathbf{4}$ indicates that the triazole bridge, as opposed to the alkynyl bridge, efficiently blocks electron transfer towards the Rh center.
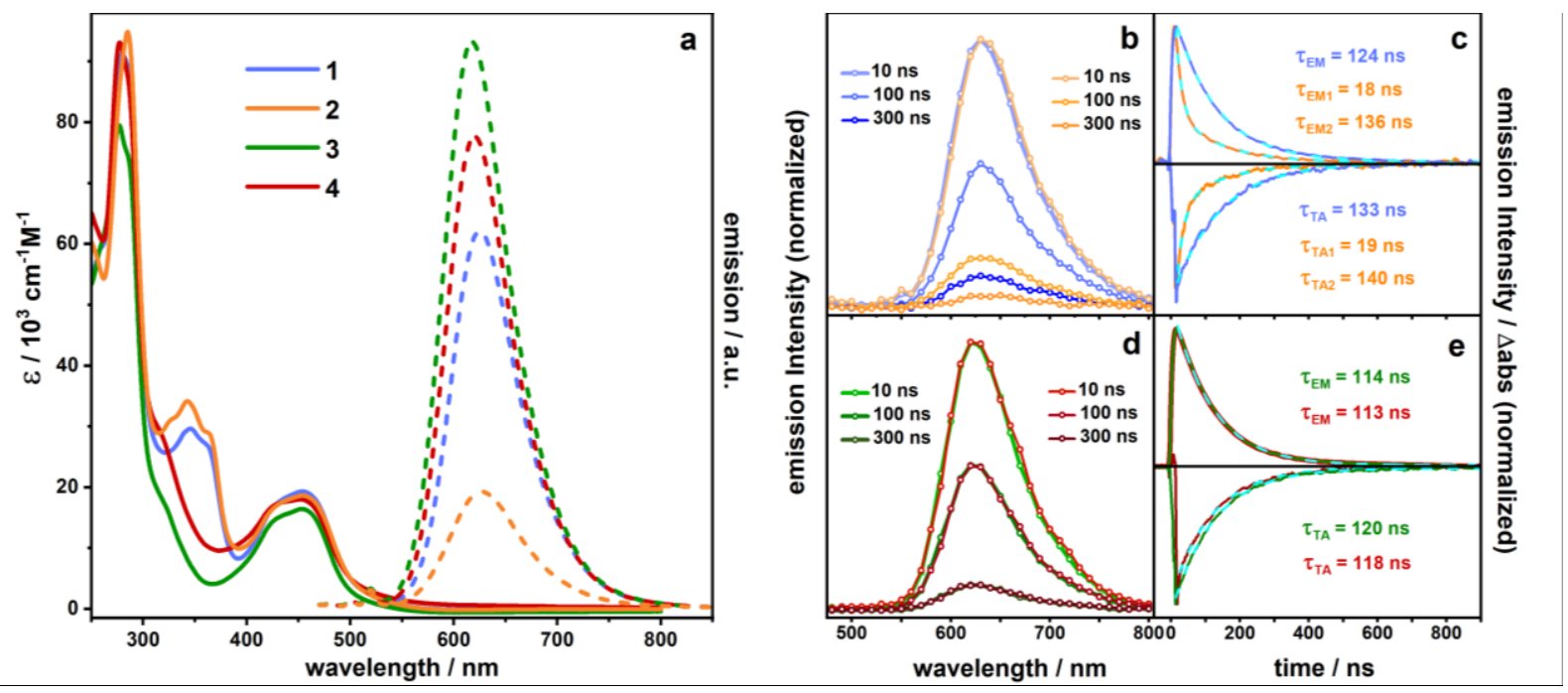

Figure 4: A: UV/vis absorption (solid) and emission (dashed) spectra $\left(\lambda_{\text {exc }}=450 \mathrm{~nm}\right)$ of the samples. $B$ and D: Time resolved emission spectra of $\mathbf{1}$ (blue), $\mathbf{2}$ (orange), $\mathbf{3}$ (green) and $\mathbf{4}$ (red) (experimental data) in acetonitrile excited at $470 \mathrm{~nm}$. C and E: Emission decay profiles of the transient species and normalized transient absorption kinetic traces recorded in the region of the ground state bleach at $450 \mathrm{~nm}$ and the corresponding fit (cyan, dashed). The respectively fitted emission and transient absorption lifetimes are indicated in the plots.

\section{Catalysis.}

To evaluate the photocatalytic performance of the novel heterodinuclear RuRh catalysts ( 2 and $\mathbf{4})$, first the principal activity of the catalytic center towards $N A D^{+}$reduction was considered. This was accomplished by running light-independent thermal catalysis with sodium formate as reducing agent, which allowed to derive the effect of different bridging ligands on the efficiency of the structurally similar catalytic centers for nicotinamide reduction. 
Activity of the Catalytic Center. Thermal, formate-driven NAD+ reduction by 2,4 and previously reported $\left[(\text { tbbpy })_{2} \mathrm{Ru}(\mathrm{tpphz}) \mathrm{Rh}\left(\mathrm{Cp}^{*}\right) \mathrm{Cl}\right] \mathrm{Cl}\left(\mathrm{PF}_{6}\right)_{2}(\mathbf{5})^{20}$ used as reference was performed at $25-50{ }^{\circ} \mathrm{C} .{ }^{25,52}$ The effect of different temperatures on the catalytic activity was screened in intervals of $5^{\circ} \mathrm{C}$ (Figure S10). All three complexes performed equally over the investigated temperature range and showed temperature dependence (Figure 5) in accordance with an Arrhenius plot (Figure S11). The average turnover frequency (TOF) during catalysis increased 19 -fold from $25^{\circ} \mathrm{C}$ to $50^{\circ} \mathrm{C}$ for 2,4 and $\mathbf{5}$, respectively. This equivalent behavior between all three heterodinuclear complexes $\mathbf{2 , 4}$ and $\mathbf{5}$ shows that the catalytic activity of the rhodium center is determined by the phenanthroline coordination, while the actual structure of the investigated modular bridging ligands does not influence the catalytic properties of the Rh center. This is in line with the very similar redox potentials of the $\mathrm{Rh}^{\prime \prime \prime} / \mathrm{Rh}^{\prime}$ couples of the dinuclear complexes ${ }^{53}$ (see Table S2) and thus allows to assign the different photocatalytic activities of the systems (vide infra) to the distinct design of the bridging ligands.
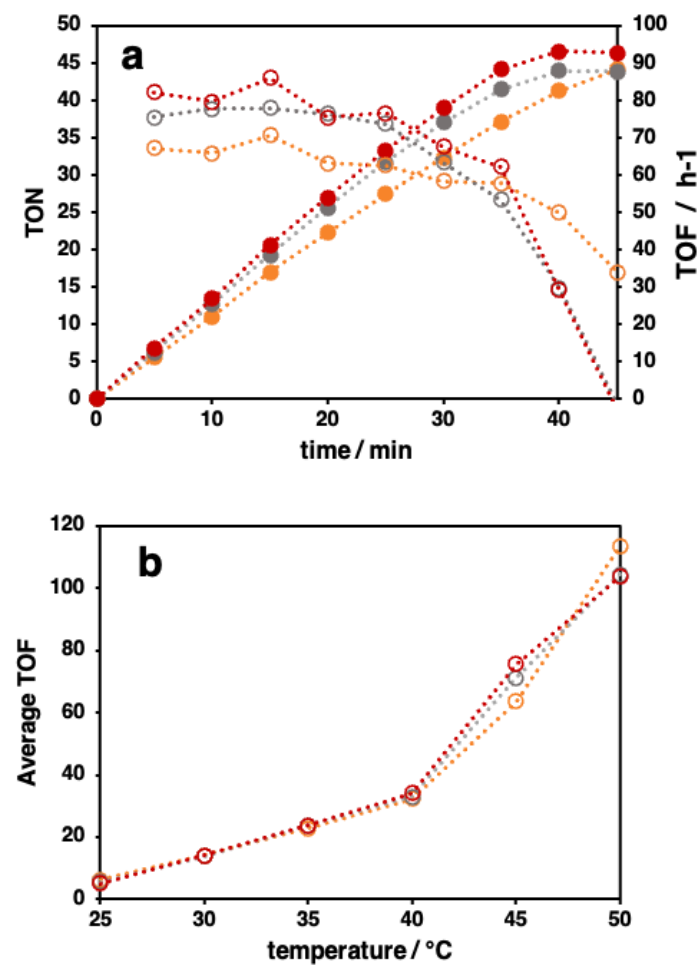

Figure 5 (A) TONs (solid dots, dotted lines as visual aid) and TOFs (hollow dots, dotted lines as visual aid) during formate driven catalysis at $45^{\circ} \mathrm{C}$ of complexes 2 (orange), 4 (red), and 5 (grey). $\left(\mathrm{H}_{2} \mathrm{O} /\right.$ acetonitrile 9/1 (v/v), $50 \mathrm{mM} \mathrm{NaHCO}, 5 \mu \mathrm{M}$ catalyst, $250 \mu \mathrm{M} \mathrm{NAD}$ ) (B) average TOF (within 90 minutes or until substrate limitation) during formate driven catalysis of complexes 2 (orange), 4 (red), and $\mathbf{5}$ (grey) at temperatures ranging from $25^{\circ} \mathrm{C}$ to $50{ }^{\circ} \mathrm{C}$ (dotted line added as a visual aid). 
In-situ UV/vis spectroscopy. The first step in the photocatalytic mechanisms is the photochemical

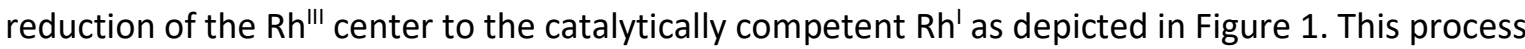
can easily be monitored with UV/vis spectroscopy. ${ }^{24}$ Sample solutions in acetonitrile were irradiated at $470 \mathrm{~nm}$ in presence of TEA as sacrificial donor. Photochemical reduction of the catalysts yield the $\mathrm{Rh}^{\prime}$ species, which reveal a broad absorption band at $680 \mathrm{~nm}$ due to a $\mathrm{Rh}^{\prime} \rightarrow$ phen MLCT transition. ${ }^{24}$ An in situ monitoring of the absorbance at $680 \mathrm{~nm}$ thus allows us to study the concentration of the $\mathrm{Rh}^{\prime}$ species over time (Figure 6, S12). In $\mathbf{2}$ the rate of $\mathrm{Rh}^{\prime}$ formation during the initial 20 seconds is up to 6 times higher than in $\mathbf{4}$ and $\mathbf{5}$. Thus, by changing the molecular structure of the bridging ligand, significant differences in the formation of the catalytically competent two-fold reduced $\mathrm{Rh}^{\prime}$ intermediate can be observed. As the redox potentials for the corresponding $\mathrm{Rh}^{\prime \prime \prime} / \mathrm{Rh}^{\prime}$ couples as well as the $\mathrm{Ru}$ "II/Ru" couples do only differ among all three photocatalysts $2, \mathbf{4}$ and $\mathbf{5}$ on maximum by $70 \mathrm{mV}$ and $60 \mathrm{mV}$, respectively (see Table S2), the observed effect can clearly be associated with the bridging unit. In $\mathbf{5}$ accumulation of $\mathrm{Rh}^{\prime}$ intermediates is followed by photochemical reduction of the tpphz ligand, which further adds to the increasing absorbance at $680 \mathrm{~nm}$ at longer times. ${ }^{24}$ However, the initial rate of $\mathrm{Rh}^{\prime}$ formation in $\mathbf{5}$ is comparable to that of $\mathbf{4}$. Under the investigated conditions that resemble the ones used for photocatalytic experiments in terms of donor concentration, initially ca. $3.5 \%, 0.5 \%$ and $0.6 \%$ of the photocatalysts $\mathbf{2}, \mathbf{4}$ and $\mathbf{5}$ are doubly reduced per second which would allow ca. 130, 18 and 22 turnovers per hour as long as the photochemical reduction of the catalyst represented the rate determining step of the overall process. 


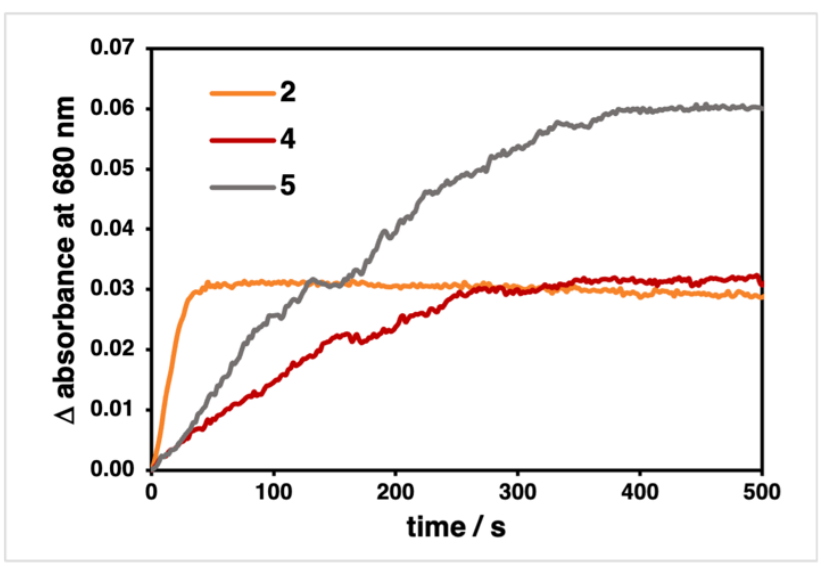

Figure 6 Absorbance at $680 \mathrm{~nm}$ during irradiation $\left(470 \mathrm{~nm}, 54 \mathrm{~mW} / \mathrm{cm}^{2}\right)$ of deaerated photocatalyst solutions (0.12 M TEA, acetonitrile/water $(1 / 9, v / v))$. Complexes 2,4 and 5 are represented by orange, red and gray solid lines, respectively.

Photocatalysis. Above it was shown that all three RuRh complexes did show very similar behavior in the thermal catalytic process using sodium formate as chemical reductant. Furthermore, having established that the photochemical formation of the catalytically competent $\mathrm{Rh}^{\prime}$ state is feasible in all three heterodinuclear complexes with very different kinetics, we investigated their potential in lightdriven catalysis. It was already established with the experiments of the thermal formate-driven catalysis that the catalytic performance of the rhodium center is strongly influenced by temperature. Thus, also for the photocatalytic reactions using triethylamine as sacrificial reductant, a temperature range between $25^{\circ} \mathrm{C}$ and $50^{\circ} \mathrm{C}$ was screened in $5^{\circ} \mathrm{C}$ intervals.

For the light-independent reaction discussed above, $\beta$-hydride elimination from metal bound formate has been shown to represent the rate-limiting step (see Figure S9). ${ }^{52}$ Nevertheless, also for the hydride transfer from the reductively activated Rh center to the nicotinamide substrate, a nonnegligible kinetic barrier might exist. Thus, albeit following a slightly different mechanism (see Figures 1 and S13) avoiding the energy demanding $\beta$-hydride elimination step, also photocatalysis was anticipated to display temperature dependence. However, a large effect of thermal acceleration on the photocatalytic reaction would only be observable if the necessary two-fold photochemical reduction of the catalyst is significantly faster than catalytic turnover at the Rh center itself. Otherwise photochemical two-fold reductive activation of the Rh center would represent the bottleneck of the overall photocatalytic process. 
As shown in Figure 7a, of the three photocatalysts $\mathbf{2 , 4}$ and $\mathbf{5}$ the alkyne moiety containing system $\mathbf{2}$ exhibited the highest initial TOF which also led for most investigated temperatures to the highest TON after $90 \mathrm{~min}$ (see Figure $7 \mathrm{~b}$ ). To ensure that the catalytic process proceeded at all temperatures with the same regioselectivity for the NADH formation, emission spectroscopy was employed to monitor the purity. For all three systems the NADH formation selectivity is close to $100 \%$ (see Table S3). Moreover, a strong temperature dependence on the photocatalytic reaction rate was observed for 2 . Between $25^{\circ} \mathrm{C}$ and $50{ }^{\circ} \mathrm{C}$, the initial reaction rate was increased 6.5 -fold, whereas for the other heterodinuclear complexes $\mathbf{4}$ and $\mathbf{5}$ this increase was only 2.5 -fold. However, between $25^{\circ} \mathrm{C}$ and $45^{\circ} \mathrm{C}$, the increase of the initial photocatalytic reaction rate for all three complexes was ca. 2.5-fold.

Photocatalyst $\mathbf{2}$ is the only catalyst which exhibited a faster initial catalytic NADH formation in the photocatalytic approach compared to the formate-driven thermal catalysis (see Figure 5b). This is opposite to catalysts $\mathbf{4}$ and $\mathbf{5}$ which performed worse in the photocatalysis compared to thermal catalysis.

In order to explain why the vastly different initial TOF values of the various catalysts did not affect the TON after 90 min to an equal degree, we performed detailed catalytic measurements at different temperatures, see Figures 7c-d. Whereas the tpphz bridged catalyst 5 produced NADH in a nearly constant rate, novel photocatalysts $\mathbf{2}$ and $\mathbf{4}$ exhibited significantly decreasing photocatalytic output with progressing irradiation time. As 2 reaches substrate limitation at $50^{\circ} \mathrm{C}$ already after 20 minutes, we increased the substrate concentration by a factor of 4 . However, this led to an increase in attainable TONs to 60 , i.e. by only $42 \%$ (Figure S15). 

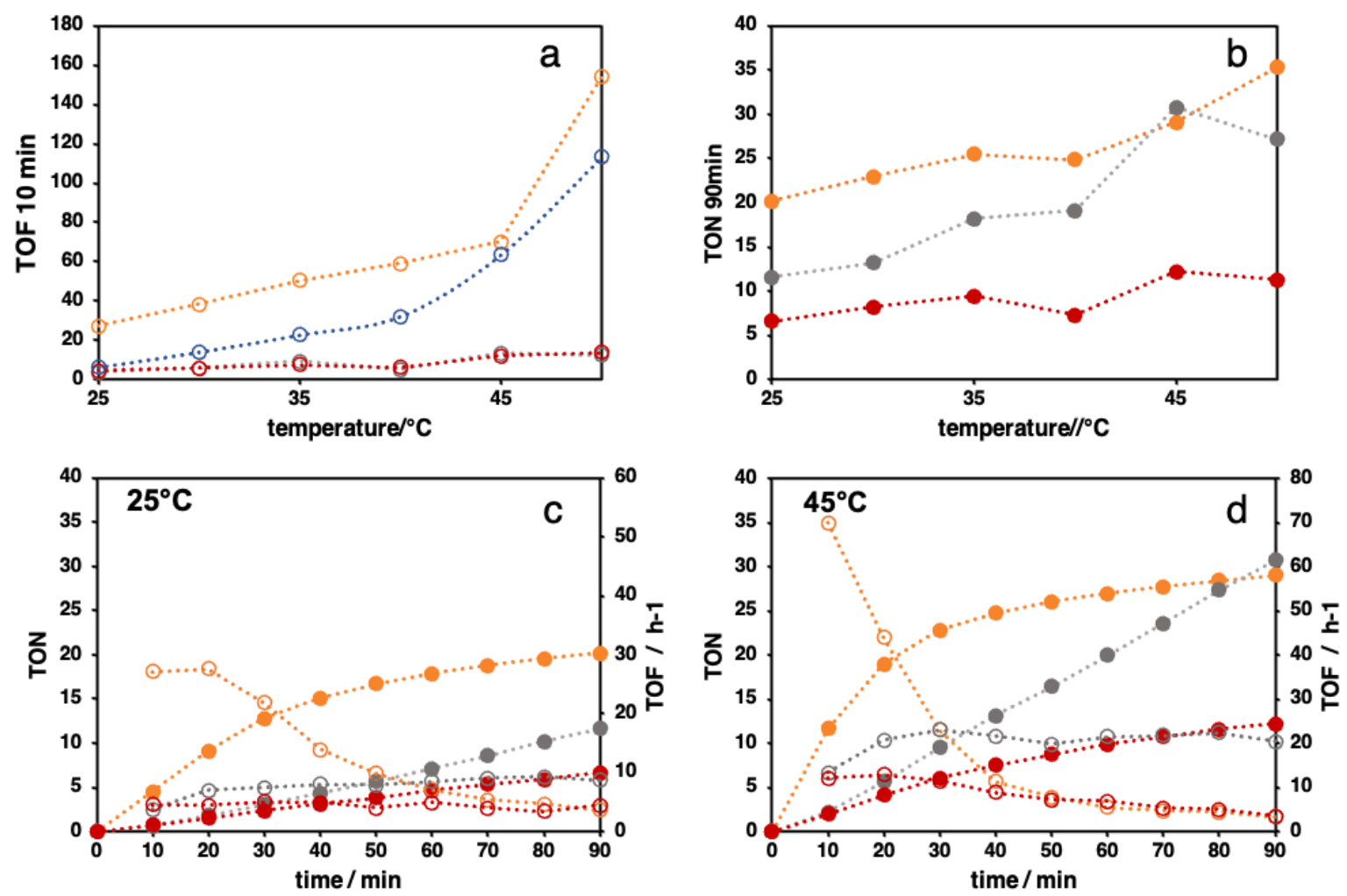

Figure 7 Temperature dependent photocatalysis of complexes 2 (orange), $\mathbf{4}$ (red) and $\mathbf{5}$ (grey). TON as solid dots, TOF as hollow dots (dotted lines added as a visual aid). (A) Temperature dependent TOF within the first 10 minutes of photocatalysis. Average TOF of 2, 4, 5 (within 90 minutes or until substrate limitation) in formate driven catalysis (blue) for comparison. (B) TON after 90 minutes of photocatalysis for the three complexes $\left(\mathrm{H}_{2} \mathrm{O} /\right.$ acetonitrile $2 / 1 \mathrm{v} / \mathrm{v}, 0.12 \mathrm{M}$ TEA, $0.1 \mathrm{M} \mathrm{NaH}_{2} \mathrm{PO}_{4}, 5 \mu \mathrm{M}$ catalyst, $250 \mu \mathrm{M} \mathrm{NAD}$ ). (C) Photocatalysis at $25^{\circ} \mathrm{C}(\mathrm{D})$ Photocatalysis at $45^{\circ} \mathrm{C}$

In order to identify important deactivation pathways of catalyst $\mathbf{2}$ under photocatalytic conditions the alkynyl vibration was monitored in resonance Raman experiments (i) first during irradiation with $405 \mathrm{~nm}$ (0.12 M TEA, acetonitrile/water, 1/2, v/v) (Figure S20a) and (ii) second in presence of a proton source (TFA) during reduction of the catalytic center (Figure S20b). The significant loss of the alkynyl band intensity at $2200 \mathrm{~cm}^{-1}$ upon irradiation of $\mathbf{2}$ under catalytic conditions and during electrochemical reduction in presence of protons proves the loss of the activity boosting alkynyl functionality as one important deactivation pathway.

From experimental design of the resonance Raman experiments it is thus concluded that hydrogenation of the alkynyl bridge occurs. This may take place either by a hydride donating Rh species ${ }^{19}$ or by consecutive reactions induced by an excess of electrons stored on the bridging ligand upon photoexcitation and in the presence of protons. To corroborate these findings by additional 
experimental evidence, we performed catalysis experiments in absence of substrate while monitoring the absorption spectra of the catalyst. During formate driven catalysis conditions of complex $\mathbf{2}$, the $\pi-\pi^{*}$ band, which we assign to the conjugated bridging ligand of complex $\mathbf{2}$, degrades within 60 minutes (Figure S20a), suggesting loss of the interconnecting alkyne functionality by a hydride donating Rh species. This can be replicated by an intramolecular approach for complex $\mathbf{1}$ if [(phen) RhCp* $\mathrm{Cl}] \mathrm{Cl}$ is used as hydrogenation catalyst under similar conditions (Figure S2Ob). The same behavior, although significantly faster can be found for $\mathbf{2}$ upon irradiation under photocatalytic conditions in the absence of substrate (Figure S20c). Subsequent addition of substrate to this solution after photochemical loss of the alkyne functionality led to a catalytic performance similar to that of late stages of catalysis for complex 2 (Figure 7, S20d).

Photoinduced Charge Transfer Dynamics. To corroborate the catalytic evaluation of the catalysts with mechanistic information on the intramolecular light-driven charge transfer we will now consider resonance Raman and transient absorption spectroscopy. ${ }^{24}$

Resonance Raman spectroscopy. Resonance Raman (rR) spectra reveal the structure of the FranckCondon point of absorption and as such the starting geometry for electron transfer in the electronically excited state. rR spectra of 1-4 have been recorded at $405 \mathrm{~nm}$ and $473 \mathrm{~nm}$ excitation, i.e. in resonance with the ${ }^{1} \mathrm{MLCT}$ transition, and reveal characteristic differences between the complexes bearing the alkyne and the triazole linkage. This is exemplified in Figure 8, which compares the $r R$ spectra with the spectrum of $\left[\mathrm{Ru}(\mathrm{tbbpy})_{2}(\mathrm{phen})\right]\left(\mathrm{PF}_{6}\right)_{2}$ as reference. 

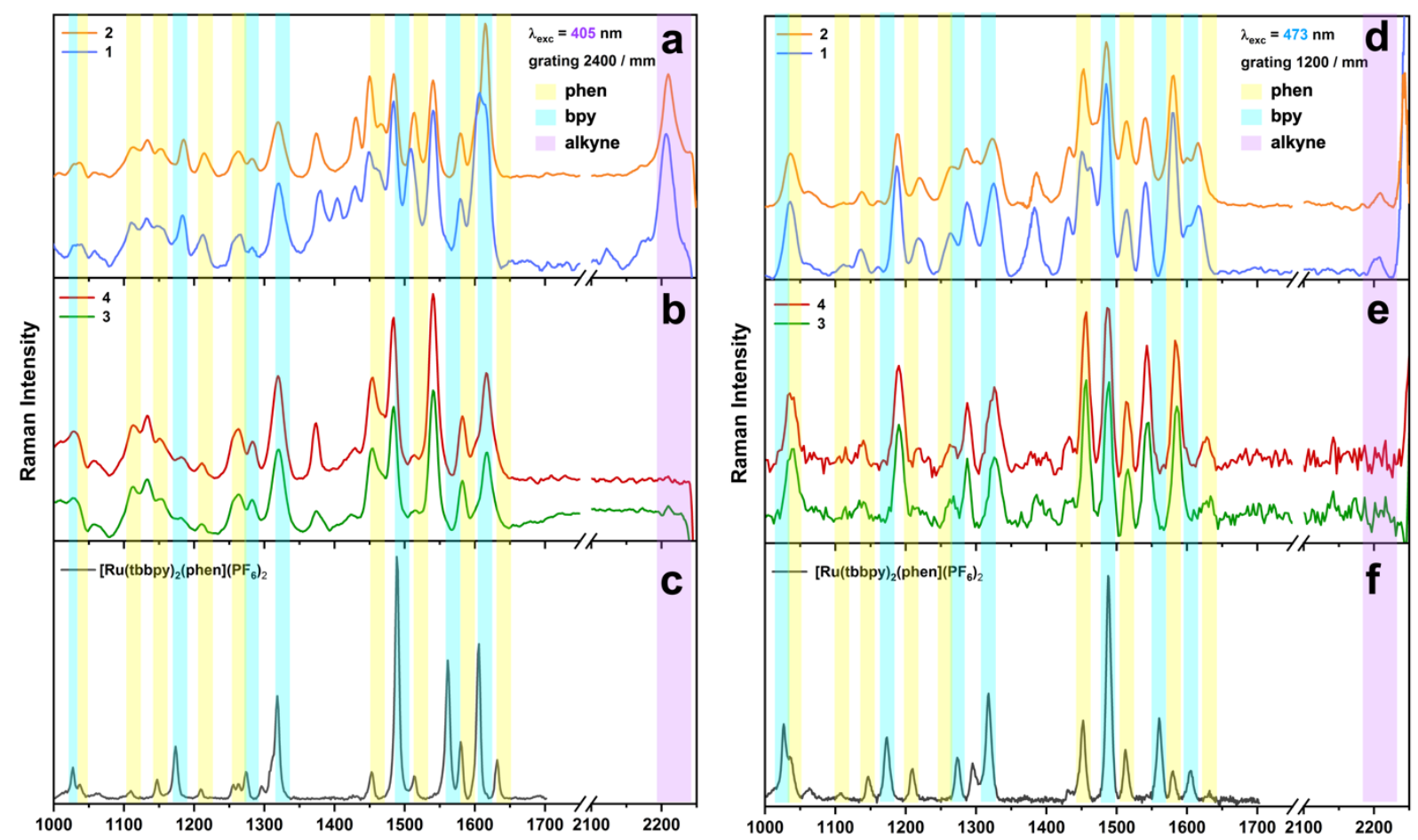

Figure 8: RR spectra of 1 and 2 in acetonitrile upon excitation at $405 \mathrm{~nm}$ (a) and $473 \mathrm{~nm}$ (d). RR spectra of 3 and $\mathbf{4}$ in acetonitrile excited at $405 \mathrm{~nm}$ (b) and $473 \mathrm{~nm}$ (e). RR spectrum of [Ru(tbbpy) 2 (phen)] $]^{2+}$, excited at $405 \mathrm{~nm}$ (c) and $473 \mathrm{~nm}(f)$ for comparison. Characteristic Raman modes assigned to bipyridine, phenanthroline and alkyne are highlighted in blue, yellow and purple, respectively.

First, the spectra of triazole moiety containing $\mathbf{3}$ and $\mathbf{4}$ are very similar irrespective of the excitation wavelengths (Figures $8 \mathrm{~b}$ and e). In addition, the spectra closely resemble the spectrum of the reference compound $\left[\mathrm{Ru}(\mathrm{tbbpy})_{2} \text { phen }\right]^{2+}\left(\right.$ compare Figures $8 \mathrm{~b}$ and $\mathrm{c}$, e and f). ${ }^{39,54-57}$ This indicates that the localization of the Franck-Condon region and spatial extension of the ${ }^{1} \mathrm{MLCT}$ state within the complexes remains unchanged upon introducing the (phen) $\mathrm{RhCp}^{*} \mathrm{Cl}$ (or the phen fragment only) via Click-chemistry. The situation is different for $\mathbf{1}$ and $\mathbf{2}$, for which the Raman spectra are not only distinct from each other, e.g., at around $1400 \mathrm{~cm}^{-1}, 1450 \mathrm{~cm}^{-1}$ and $1600 \mathrm{~cm}^{-1}$, but also differ from $\left[\mathrm{Ru}(\mathrm{tbbpy})_{2} \text { phen }\right]^{2+}$. Specifically, the relative intensity ratio of the Raman bands is different, e.g., the strongest band of [Ru(tbbpy) ${ }_{2}$ phen $]^{2+}$ at $1490 \mathrm{~cm}^{-1}$ at $405 \mathrm{~nm}$ excitation is weaker than the bands at 1550 and $1600 \mathrm{~cm}^{-1}$ in the alkyne linked complexes. This indicates, that the ${ }^{1} \mathrm{MLCT}$ of the alkynelinked complexes differs from the ${ }^{1} \mathrm{MLCT}$ of $\left[\mathrm{Ru}(\text { tbbpy })_{2} \text { phen }\right]^{2+}$. The $-\mathrm{C} \equiv \mathrm{C}$ - triple bond stretching vibration is visible as a prominent band in the resonance Raman spectrum both in $\mathbf{1}$ and in $\mathbf{2}$ at $405 \mathrm{~nm}$ and as weak band at $473 \mathrm{~nm}$ excitation. This indicates that the $-\mathrm{C} \equiv \mathrm{C}$ - motif allows for interaction of the two phen spheres in the ${ }^{1} \mathrm{MLCT}$ localized on the bridging ligand. We speculate that 
the ${ }^{1} \mathrm{MLCT}$ is delocalized across the $-\mathrm{C} \equiv \mathrm{C}$ - bridge, and hence has distinctly different spectral features than in $\left[\mathrm{Ru}(\mathrm{tbbpy})_{2} \text { phen }\right]^{2+}$. This is in line with results on the first reduction of 1, i.e. reduction of the bridging ligand, in a spectroelectrochemical resonance Raman experiment. ${ }^{24,54,58-64}$ Here the vibrational mode associated with the $-\mathrm{C} \equiv \mathrm{C}$ - triple bond is shifted to lower wavenumbers upon reduction (Figure S21). This further corroborates that extension of the phen-ligand by the alkynyl functionality extends the chromophoric system of the ligand enabling it to function as an electron acceptor in a MLCT transition even if reduced once by electrochemical means. ${ }^{64}$ The downshift of the respective vibrational mode upon reduction of 1 reflects the increased electron density across the $\mathrm{C} \equiv \mathrm{C}$ - triple bond upon electrochemical reduction of the complex. Another spectral feature is the band at $1400 \mathrm{~cm}^{-1}$, which is only visible in 1 upon $405 \mathrm{~nm}$ excitation. We associate the band with a C$\mathrm{N}$ vibration of uncoordinated phenanthroline ligand. Upon complexation with the $\mathrm{RhCp} * \mathrm{Cl}$ center the band disappears. The absence of the $1400 \mathrm{~cm}^{-1}$ band in the $\mathrm{rR}$ spectrum of 1 recorded upon $473 \mathrm{~nm}$ excitation shows a less extended ${ }^{1} \mathrm{MLCT}$ upon red-shifting the excitation wavelength.

Femtosecond pump-probe spectroscopy. To investigate differences not only in the initially populated ${ }^{1} \mathrm{MLCT}$ state but also in the subsequent intramolecular relaxation, femtosecond transient absorption spectroscopy was performed in acetonitrile and dichloromethane upon excitation at 400 and at $470 \mathrm{~nm}$, i.e. in the high and low energy flank of the ${ }^{1} \mathrm{MLCT}$ absorption band. Reminiscent of the findings from the $\mathrm{rR}$ data, triazole bridged $\mathbf{3}$ and $\mathbf{4}$ reveal an excited state dynamics, which is very much alike the dynamics observed for $\left[\mathrm{Ru}(\mathrm{bpy})_{2} \mathrm{phen}\right]^{2+}$. The corresponding data is summarized in Figures S22-S25. Irrespective of the $\mathrm{RhCp}{ }^{*} \mathrm{Cl}$ center being present or not, the ground state bleach, reflecting the ${ }^{1} \mathrm{MLCT}$ absorption band, is accompanied by a broad and unstructured excited state absorption at wavelengths longer than ca. $500 \mathrm{~nm}$, which stems from ligand-to-metal charge transfer transitions, characteristic for ${ }^{3} \mathrm{MLCT}$ states in $\left[\mathrm{Ru}(\mathrm{bpy})_{2} \text { phen }\right]^{2+}$ complexes. ${ }^{40,65,66}$ The more intense excited state absorption at $c a .360 \mathrm{~nm}$ is due to $\pi \pi^{*}$ transitions of the reduced phen-sphere - also characteristic for $\left[\mathrm{Ru}(\mathrm{bpy})_{2} \text { phen }\right]^{2+}$ complexes. ${ }^{40,67}$ The transient absorption data - irrespective of 
solvent and excitation wavelength - show that excited state relaxation in $\mathbf{3}$ and $\mathbf{4}$ does not involve the peripheral phen motif or the (phen) $\mathrm{RhCp}^{*} \mathrm{Cl}$ center, respectively. Thus, the data line up with the emission data (see Figure 4), which show comparably high emission of $\mathbf{3}$ and $\mathbf{4}$, barely influenced by the introduction of the $\mathrm{RhCp} * \mathrm{Cl}$ center.
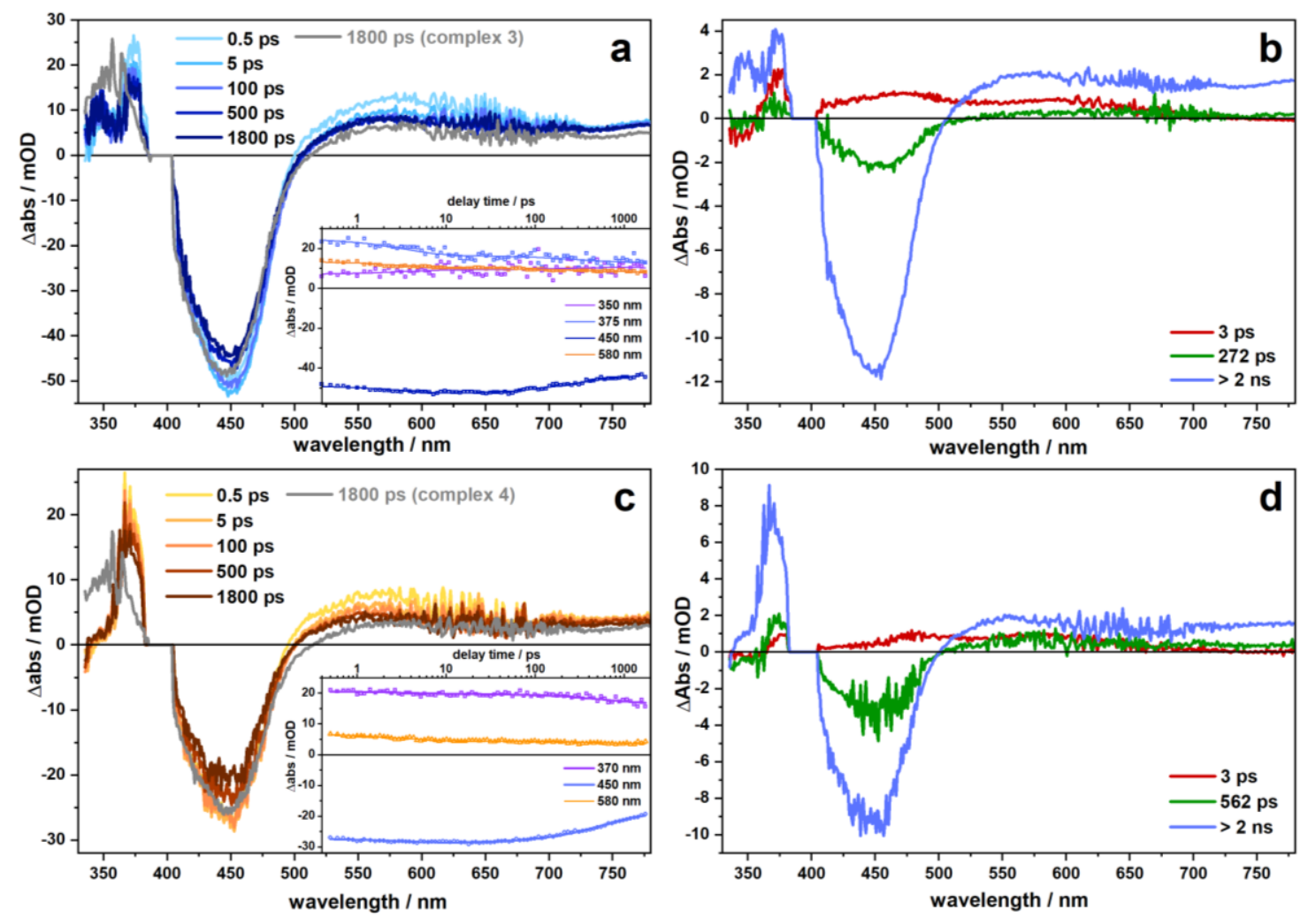

Figure 9: Transient absorption spectra recorded for $\mathbf{1}$ (a) and $\mathbf{2}$ (c) in acetonitrile upon pumping at $400 \mathrm{~nm}$ at different delay times. Kinetic traces of $\mathbf{1}$ (Inset in a) and $\mathbf{2}$ (Inset in c) at selected wavelength. Decay-associated spectra and corresponding time constants of $\mathbf{1}(b)$ and $\mathbf{2}(d)$ derived from a global multiexponential fit applied on the transient absorption data. 

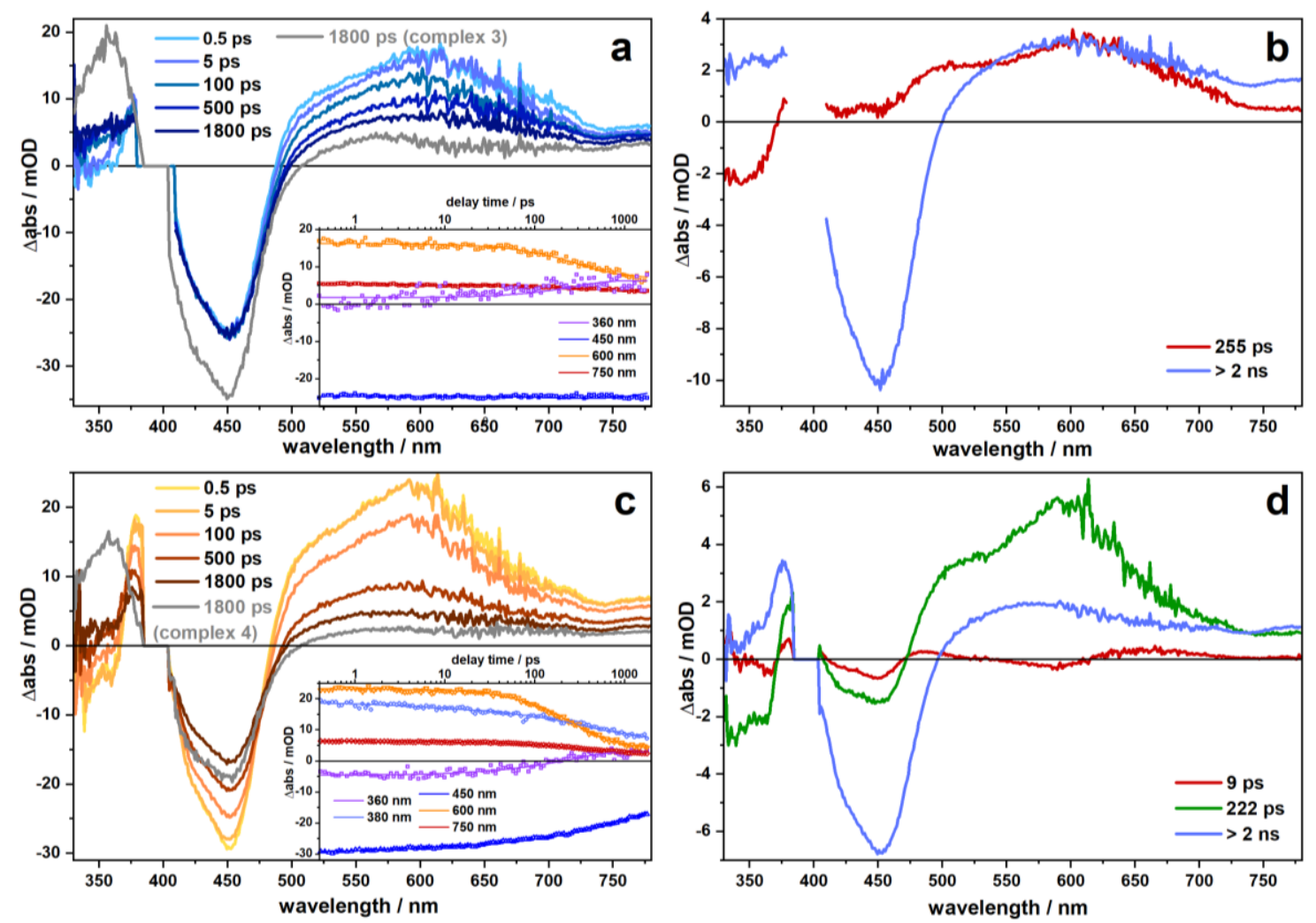

Figure 10: Transient absorption spectra recorded for $\mathbf{1}(\mathrm{A})$ and $\mathbf{2}(\mathrm{C})$ in dichloromethane upon pumping at $400 \mathrm{~nm}$ at different delay times. Kinetic traces of $\mathbf{1}$ (Inset in A) and $\mathbf{2}$ (Inset in C) at selected wavelength. Decay-associated spectra and corresponding time constants of $\mathbf{1}(B)$ and $\mathbf{2}(D)$ derived from a global multiexponential fit applied on the transient absorption data. (C)

The transient absorption data of $\mathbf{1}$ and $\mathbf{2}$ are shown in Figures 9 and 10. Compared to the spectra of $\mathbf{3}$ and 4, the pronounced transient absorption feature at $360 \mathrm{~nm}$, characteristic for the $\pi \pi^{*}$ absorption of the reduced phen, is absent. Instead, a broad and flat excited state absorption is visible on the short wavelength side of the ground state bleach, indicating a more delocalized excess charge density in the long-lived ${ }^{3} \mathrm{MLCT}$ compared to $\left[\mathrm{Ru}(\mathrm{bpy})_{2} \text { phen }\right]^{2+}, \mathbf{3}$ or $\mathbf{4}$. The formation of the long-lived ${ }^{3} \mathrm{MLCT}$ state is reflected in the transient absorption kinetics. Upon excitation of the ${ }^{1} \mathrm{MLCT}$ transition at either 400 or $470 \mathrm{~nm}$ in $\mathbf{1}$ and $\mathbf{2}$, a kinetic component is visible, which is characterized by a positive $\triangle O D$ signature in the range of the ground state bleach. For $\mathbf{1}$ and $\mathbf{2}$ dissolved in dichloromethane the decay of this component is characterized by a characteristic time constant of ca. 250 ps (1) and ca. 220 ps (2, see Tables S4 and S5 for a summary of the characteristic time constants describing the kinetic components underlying the sub-ns processes in the complexes). For dichloromethane as solvent the respective component has a large spectral contribution and a characteristic maximum at about $605 \mathrm{~nm}$. This component is atypical for $\left[\mathrm{Ru}(\mathrm{bpy})_{2} \text { phen }\right]^{2+}$ complexes and is assigned to 
electronic relaxation on the alkynyl-extended phen-ligand. Spectrally, the component is associated with a decay of the phen-associated ESA at $360 \mathrm{~nm}$ and a build-up of an excited state absorption on the short-wavelength flank of the accessible probe window. For the mononuclear species 1 the longlived differential absorption spectrum shows stronger contributions below $360 \mathrm{~nm}$ than the dinuclear species 2. However, in both complexes this resulting "plateau-like structure" of the $\Delta \mathrm{OD}$ spectra below ca. $400 \mathrm{~nm}$ is distinct from the isolated differential absorption peak at $360 \mathrm{~nm}$, which is observed for 3 and 4 . In addition, the 220 ps/250 ps component causes a red-shift of the ESA in the visible, which also becomes increasingly flat and unstructured during the underlying process. Keeping in mind the rR spectra indicating excitation of a ${ }^{1} \mathrm{MLCT}$ state, which is already initially delocalized involving the $-\mathrm{C} \equiv \mathrm{C}$ - bond, and the reduced emission yield of $\mathbf{1}$ and $\mathbf{2}$, we assign the $220 \mathrm{ps} / 250 \mathrm{ps}$ processes to charge-density relaxation on the bridging-ligand. This charge density relaxation redistributes the electron density over the two phen spheres and as a consequence a long-lived ${ }^{3} \mathrm{MLCT}$ state is formed, which shows altered ligand-associated $\pi \pi^{*}$ absorption. The different spectral contributions at below $360 \mathrm{~nm}$, when comparing 1 and $\mathbf{2}$, might indicate an enhanced charge localization on the phenanthroline of the (phen) $\mathrm{RhCp} * \mathrm{Cl}$ fragment upon $\mathrm{Rh}$ coordination.

Also for 1 dissolved in the more polar solvent acetonitrile the "plateau-like structure" of the $\triangle O D$ spectra below ca. $400 \mathrm{~nm}$ is visible at long delay times, indicating that a similar long-lived state is populated as in dichloromethane. However, the characteristic kinetic processes yielding the build-up of this long-lived state are different. A sub-10 ps component (the actual value depending on the pump wavelength, for comparison see Figures S26 and S27) jointly with a 280 ps reflect (i) a decay of an ESA in the range of the GSB, reminiscent of the spectral features causing the red-shift of the ESA in the visible spectral range for $\mathbf{1}$ in dichloromethane and (ii) the decay of the phen-associated ESA at $360 \mathrm{~nm}$ and a build-up of ESA on the short-wavelength flank of the accessible probe wavelength. For $\mathbf{2}$ dissolved in acetonitrile the data indicates only minor ground state recovery and the loss of the ESA peak at ca. $570 \mathrm{~nm}$, yielding a long-lived species, whose UV-ESA reveals a localized phen ${ }^{\bullet}$ radical. Taken together with the $\mathrm{rR}$ data indicating an initially excited state being delocalized over the $-\mathrm{C} \equiv \mathrm{C}-$ 
band of the bridging ligand and the minute emission intensity of $\mathbf{2}$ we suggest that the phen ${ }^{\circ}$ radical is centered on the (phen) $\mathrm{RhCp} * \mathrm{Cl}$ sphere. The localization of the excess electron density of the longlived ${ }^{3} \mathrm{MLCT}$ state in $\mathbf{2}$ on the (phen) $\mathrm{RhCp} * \mathrm{Cl}$ fragment of the complex is assisted by the high polarity of the solvent favoring the population of electronic states with increased dipole moments.

Considering the spectroscopic characterization, we would like to point out that for $\mathbf{1}$ and $\mathbf{2}$ the excited state electron density already at the Franck-Condon point of absorption is (partially) extended over the alkynyl bond. In contrast, the rR spectra of $\mathbf{3}$ and $\mathbf{4}$ strongly resemble the spectrum of the reference compound $\left[\mathrm{Ru}(\mathrm{tbbpy})_{2} \text { phen }\right]^{2+}$, i.e. pointing to the access electron density being localized on the phen-sphere coordinating the Ru ion at the Franck-Condon point. Also, the emission properties of $\mathbf{3}$ and $\mathbf{4}$ are essentially similar, while coordination of the Rh center to $\mathbf{1}$ (yielding 2) yields to a fast $18 \mathrm{~ns}$ emission deactivation component. We relate this additional emission decay channel to electron transfer from the emissive ${ }^{3} \mathrm{MLCT}_{\text {phen, }}$, with its access electron density localized on the phen-sphere coordinating the $\mathrm{Ru}$, to the coordination sphere of the $\mathrm{Rh}$ center - an electron transfer that is apparently inhibited in the presence of the triazole-bridge. Judging by the same lifetimes as obtained from time-resolved emission and ns time-resolved transient absorption experiments, the charge separated state is short lived, such that its decay is hidden beneath its 18 ns formation kinetics.

The pivotal role of the bridging architecture is also reflected in the sub-ns transient absorption kinetics. This kinetics show a charge density shift within the bridging ligand of 1 and $\mathbf{2}$ (220 ps/250 ps component, respectively) likely associated with structural relaxation of the alkynyl bridge. As inferred from the excited state absorption band below $400 \mathrm{~nm}$, this charge density shift leads to a partial electron transfer from the phenanthroline sphere coordinating the Ru ion to the secondary coordination sphere. This charge density shift diminishes the contribution of $\mathrm{Ru}-{ }^{3} \mathrm{MLCT}$ phen to the long-lived excited state and consequently reduces the emission quantum yields of $\mathbf{1}$ and $\mathbf{2}$ when compared to 3 and $\mathbf{4}$. 


\section{Discussion}

As raised above, the fundamental catalytic activity of the $\left[(p h e n) R h\left(C p^{*}\right) \mathrm{Cl}\right]$ moieties towards NADH formation in the heterodinuclear complexes $\mathbf{2 , 4}$ and $\mathbf{5}$ is equal. Thus, the different photocatalytic activity can be ascribed to the impact of the altered structure of the bridging ligand on the photochemical reduction of the catalyst. The investigations on the rate of $\mathrm{Rh}^{\prime}$ formation showed (Figure 6), that in case of catalyst $\mathbf{2}$, the transfer of two electrons towards the rhodium center occurs most effectively. For the other photocatalysts $\mathbf{4}$ and $\mathbf{5}$ the photochemical formation of the $\mathrm{Rh}^{\prime}$ state was similar and approximately 6-7 times slower compared to 2 . This correlates well with the differing initial TOF values obtained in the photocatalytic process, where 2 performed ca. 6 times faster than the two other investigated systems. Thus, it is evident that the improved photocatalytic activity of 2 is due to its superior ability to photochemically form the active $\mathrm{Rh}^{\prime}$ state.

Moreover, the strong increase in the rate of NADH formation of 2 between $45^{\circ} \mathrm{C}$ and $50{ }^{\circ} \mathrm{C}$ might indicate that only after this additional thermal input, catalytic turnover at the Rh center is sufficiently fast to keep up with the efficient photochemistry of the system and to release its full potential. This is well-reflected by the results of the photochemical reduction of $\mathbf{2}$ (Figure 6) which suggested a TOF of at least ca. $130 \mathrm{~h}^{-1}$ under only photochemistry-limited conditions. Thus, at lower temperatures than $50^{\circ} \mathrm{C}$, the catalytic turnover at the Rh center limits the photocatalytic NADH formation rate of the overall process in catalyst $\mathbf{2}$.

However, it should be noted that the rate of forming the $\mathrm{Rh}^{\prime}$ state is not strictly correlating with the rate of the first electron transfer to the Rh center. Albeit this is true when comparing novel photocatalysts $\mathbf{2}$ and $\mathbf{4}$, the previously reported tpphz based system does not follow this trend. In the latter photochemical reduction of the $\mathrm{Rh}^{\text {III }}$ center with the first electron occurs within less than $0.5 \mathrm{~ns}^{24}$ In order to explain the observed differences in forming the $\mathrm{Rh}$ ' state it is thus clear that 
other factors need to be considered as well such as charge recombination rates or electronic communication between the two metal centers in their onefold or twofold reduced intermediates. ${ }^{24}$ Lastly, the different time profiles of the photocatalytic NADH formation among the three investigated catalysts moreover indicates that the stabilities of the systems are vastly different. Whereas the tpphz based catalyst $\mathbf{5}$ generates NADH with a constant TOF, novel compounds $\mathbf{2}$ and $\mathbf{4}$ show a decreasing activity with increasing irradiation time. Although by increasing substrate availability 4fold an increase of the overall TON by more than $40 \%$ was observed for catalyst 2 , the catalyst deactivates rather rapidly within about 20 minutes. By the various experimental evidence presented above, it is concluded that loss of the alkyne functionality via a hydrogenation process is one important process responsible for the inactivation. Thus, by replacing the tpphz bridging ligand with the new alkyne bridged bis-phenanthroline motif, long-term stability is lost but efficient catalysis for a short period of time is gained.

\section{Conclusion}

In summary we presented two novel heterodinuclear [(tbbpy $\left.{ }_{2} \mathrm{Ru}-\mathrm{BL}-\mathrm{Rh}(\mathrm{Cp} *) \mathrm{Cl}\right]^{3+}$ photocatalysts 2 and $\mathbf{4}$ which were spectroscopically analyzed in detail. Moreover, the heterodinuclear complexes were used for selective thermal and photocatalytic formation of biologically relevant NADH and the efficiency of this process was compared to a known benchmark photocatalyst (5).

It was shown that the actual molecular structure of the unit connecting the two phenanthroline spheres of the bridging ligands drastically impacts the photophysical properties as well as the photocatalytic activity. Whereas the alkyne linker in $\mathbf{2}$ allows for intramolecular electron transfers to the Rh center via formation of a ${ }^{3} \mathrm{MLCT}$ state involving the triple bond within ca. $20 \mathrm{~ns}$, the triazole in contrast acts as an insulator prohibiting similarly efficient reductive activation of the catalyst via an oxidative quenching pathway. 
Furthermore, as the thermal catalytic activity of all three complexes was very similar these catalysts proved to be ideally suited for a detailed comparison of the impact of the linking strategy within the bridging ligand on their photocatalytic activity. An important finding was, that the rate of photochemical formation of the two-electron reduced, catalytically fully competent $\mathrm{Rh}^{\prime}$ center could directly be correlated with the photocatalytic activity. For the less active triazole and phenazine linked systems $\mathbf{4}$ and $\mathbf{5}$, sluggish photochemical activation of the catalyst was identified as the major activity limiting step. In contrast, at temperatures up to $45^{\circ} \mathrm{C}$, catalytic turnover at the photochemically activated Rh center in the alkyne linked system 2 represented its bottleneck. Nevertheless, by circumventing the energy demanding $\beta$-hydride elimination of metal bound formate, the light driven NADH formation by complex $\mathbf{2}$ was at every temperature investigated more efficient that the mechanistically much simpler thermal process. This highlights that by careful design of the molecular structure of supramolecular photocatalysts, photocatalytic processes are able to compete with classical light-independent catalytic processes.

Finally, in combination with the identification of deactivation processes, the easy to analyze separation of photochemical activation and catalytic turnover using $\left[(\mathrm{NN}) \mathrm{Rh}\left(\mathrm{Cp}{ }^{*}\right) \mathrm{Cl}\right]$ based supramolecular photocatalyst renders them among the best to mechanistically analyze systems. The results at hand clearly showed that for future optimized photocatalytic activity a high rate for twofold reductive activation of the Rh center - not a high rate for the first electron transfer - and chemical inertness under catalytic conditions need to be combined. 


\section{Acknowledgements}

P. Wintergerst thankfully acknowledges financial support by the Studienstiftung des deutschen

Volkes. C.M. thankfully acknowledges financial support from the Fonds der Chemischen Industrie by a a Kekulé Stipendium. Supported by the Deutsche Forschungsgemeinschaft (DFG, German Research Foundation) - Projektnummer 364549901 - TRR 234 [A1, A4]

\section{Author Contributions}

P.W. synthesized and characterized the molecules, P.W. and A.K.M. performed catalysis experiments, L.Z., C.M. and C.L. performed time dependent spectroscopy and raman experiments. P.W., L.Z., A.K.M., B.D. and S.R. wrote the manuscript with help from all other authors.

\section{Competing interests}

The authors declare no competing interests.

\section{References}

1. Armaroli, N. \& Balzani, V. The future of energy supply: Challenges and opportunities. Angewandte Chemie - International Edition 46, 52-66 (2007).

2. Lewis, N. S. \& Nocera, D. G. Powering the planet: Chemical challenges in solar energy utilization. Proceedings of the National Academy of Sciences of the United States of America 103, 15729-15735 (2006).

3. Tachibana, Y., Vayssieres, L. \& Durrant, J. R. Artificial photosynthesis for solar water-splitting. Nature Photonics 6, 511-518 (2012).

4. Halpin, Y., Pryce, M. T., Rau, S., Dini, D. \& Vos, J. G. Recent progress in the development of bimetallic photocatalysts for hydrogen generation. Dalton Transactions 42, 16243-16254 (2013).

5. Pfeffer, M. G. et al. Optimization of hydrogen-evolving photochemical molecular devices. Angewandte Chemie - International Edition 54, 6627-6631 (2015).

6. Tamaki, Y. \& Ishitani, O. Supramolecular Photocatalysts for the Reduction of CO2. ACS Catalysis 7, 3394-3409 (2017).

7. Manbeck, G. F. \& Brewer, K. J. Photoinitiated electron collection in polyazine chromophores coupled to water reduction catalysts for solar $\mathrm{H} 2$ production. Coordination Chemistry Reviews 257, 1660-1675 (2013). 
8. Karnahl, M. et al. Synthesis and photophysics of a novel photocatalyst for hydrogen production based on a tetrapyridoacridine bridging ligand. Chemical Physics 393, 65-73 (2012).

9. Karnahl, M. et al. Tuning of photocatalytic hydrogen production and photoinduced intramolecular electron transfer rates by regioselective bridging ligand substitution. ChemPhysChem 12, 2101-2109 (2011).

10. Yuan, Y. J., Yu, Z. T., Chen, D. Q. \& Zou, Z. G. Metal-complex chromophores for solar hydrogen generation. Chemical Society Reviews 46, 603-631 (2017).

11. Gholamkhass, B. et al. Architecture of supramolecular metal complexes for photocatalytic CO 2 reduction: Ruthenium-rhenium bi- and tetranuclear complexes. Inorganic Chemistry 44, 2326-2336 (2005).

12. Jiang, Y., Li, F., Huang, F., Zhang, B. \& Sun, L. Chemical and photocatalytic water oxidation by mononuclear Ru catalysts. Cuihua Xuebao/Chinese Journal of Catalysis 34, 1489-1495 (2013).

13. Noll, N. \& Würthner, F. A Calix[4]arene-Based Cyclic Dinuclear Ruthenium Complex for LightDriven Catalytic Water Oxidation. Chemistry - A European Journal 27, 444-450 (2021).

14. Ladwig, M. \& Kaim, W. Spectroscopic and electrochemical properties of the isomeric bidiazine complexes [(C5Me5) CiRh(bdz)]+ and (C5Me5) Rh(bdz) and their relevance to the catalysis of the $2 \mathrm{H}+\rightarrow \mathrm{H} 2$ reaction by 2,2'-bipyridine analogues. Journal of Organometallic Chemistry 419, 233-243 (1991).

15. Steckhan, E. et al. Analytical Study of a Series of Substituted (2,2'-Bipyridyl) (pentamethylcyclopentadienyl)rhodium and -iridium Complexes with Regard to Their Effectiveness as Redox Catalysts for the Indirect Electrochemical and Chemical Reduction of NAD(P)+. Organometallics 10, 1568-1577 (1991).

16. Kölle, U. \& Grätzel, M. Metallorganische Rhodium(III)-Komplexe als Homogenkatalysatoren für die Photoreduktion von Protonen zu Wasserstoff an kolloidalem TiO2. Angewandte Chemie 99, 572-574 (1987).

17. Quintana, L. M. A. et al. Proton-hydride tautomerism in hydrogen evolution catalysis. Proceedings of the National Academy of Sciences of the United States of America 113, 64096414 (2016).

18. Lo, H. C. et al. Regioselective reduction of NAD+ models, 1-benzylnicotinamde triflate and Bnicotinamide ribose- $5^{\prime}$-methyl phosphate, with in situ generated [ $\left.\mathrm{Cp} * \mathrm{Rh}(\mathrm{Bpy}) \mathrm{H}\right]+$ : Structureactivity relationships, kinetics, and mechanistic aspects in the formation of the 1,4-NAD. Inorganic Chemistry 40, 6705-6716 (2001).

19. Pitman, C. L., Finster, O. N. L. \& Miller, A. J. M. Cyclopentadiene-mediated hydride transfer from rhodium complexes. Chemical Communications 52, 9105-9108 (2016).

20. Mengele, A. K., Seibold, G. M., Eikmanns, B. J. \& Rau, S. Coupling Molecular Photocatalysis to Enzymatic Conversion. ChemCatChem 9, 4369-4376 (2017).

21. Hildebrand, F. \& Lütz, S. Stable electroenzymatic processes by catalyst separation. Chemistry A European Journal 15, 4998-5001 (2009).

22. Ryu, J., Nam, D. H., Lee, S. H. \& Park, C. B. Biocatalytic photosynthesis with water as an electron donor. Chemistry - A European Journal 20, 12020-12025 (2014). 
23. Choudhury, S., Baeg, J. O., Park, N. J. \& Yadav, R. K. A photocatalyst/enzyme couple that uses solar energy in the asymmetric reduction of acetophenones. Angewandte Chemie International Edition 51, 11624-11628 (2012).

24. Zedler, L. et al. Unraveling the Light-Activated Reaction Mechanism in a Catalytically Competent Key Intermediate of a Multifunctional Molecular Catalyst for Artificial Photosynthesis. Angewandte Chemie - International Edition 58, 13140-13148 (2019).

25. Ruppert, R., Herrmann, S. \& Steckhan, E. Very efficient reduction of NAD(P)+ with formate catalysed by cationic rhodium complexes. Journal of the Chemical Society, Chemical Communications 1150-1151 (1988) doi:10.1039/C39880001150.

26. Stumper, A. et al. Efficient Access to 5-Bromo- and 5,6-Dibromophenanthroline Ligands. European Journal of Inorganic Chemistry 2017, 3799-3810 (2017).

27. Wintergerst, P. et al. Minimizing Side Product Formation in Alkyne Functionalization of Ruthenium Complexes by Introduction of Protecting Groups. Zeitschrift fur Anorganische und Allgemeine Chemie 646, 1-8 (2020).

28. Wintergerst, P., Mengele, A. K., Nauroozi, D., Tschierlei, S. \& Rau, S. Impact of Alkyne Functionalization on Photophysical and Electrochemical Properties of 1,10-Phenanthrolines and Their Ru II Complexes. European Journal of Inorganic Chemistry 2019, 1988-1992 (2019).

29. Lux, F., Lemercier, G., Andraud, C., Schull, G. \& Charra, F. Self-assembled monolayers of 1,10phenanthroline based bis-bidentate ligands on au(111). Molecular Crystals and Liquid Crystals 485, 881-886 (2008).

30. Ziessel, R., Suffert, J. \& Youinou, M. T. General method for the preparation of alkynefunctionalized oligopyridine building blocks. Journal of Organic Chemistry 61, 6535-6546 (1996).

31. Ohata, J. et al. Luminogenic iridium azide complexes. Chemical Communications 51, 1519215195 (2015).

32. Ozawa, H., Haga, M. A. \& Sakai, K. A photo-hydrogen-evolving molecular device driving visiblelight-induced EDTA-reduction of water into molecular hydrogen. Journal of the American Chemical Society 128, 4926-4927 (2006).

33. Rau, S., Walther, D. \& Vos, J. G. Inspired by nature: Light driven organometallic catalysis by heterooligonuclear Ru(ii) complexes. Journal of the Chemical Society. Dalton Transactions $\mathbf{0}$, 915-919 (2007).

34. Mengele, A. K. et al. Molecular scylla and charybdis: Maneuvering between pH sensitivity and excited-state localization in ruthenium Bi(benz)imidazole complexes. Inorganic Chemistry 59, 12097-12110 (2020).

35. Karnahl, M. et al. Synthesis and Photophysical Properties of 3,8-Disubstituted 1,10Phenanthrolines and Their Ruthenium(II) Complexes. European Journal of Inorganic Chemistry 2009, 4962-4971 (2009).

36. Cauquis, G., Deronzier, A., Sillion, B., Damin, B. \& Garapon, J. Electrochemical behaviour of Nchloroparatoluene-sulphonamidate, $\mathrm{N}, \mathrm{N}$-dichloroparatoluenesulphonamide and paratoluenesulphonamide in acetonitrile. Journal of Electroanalytical Chemistry 117, 139-146 (1981). 
37. Chardon-Noblat, S., Cosnier, S., Deronzier, A. \& Vlachopoulos, N. Electrochemical properties of [(C5Me5)RhIII (L)Cl]+ complexes ( $L=2,2^{\prime}$-bipyridine or 1,10-phenanthroline derivatives) in solution in related polypyrrolic films. Application to electrocatalytic hydrogen generation. Journal of Electroanalytical Chemistry 352, 213-228 (1993).

38. Wintergerst, P. et al. Minimizing Side Product Formation in Alkyne Functionalization of Ruthenium Complexes by Introduction of Protecting Groups. Zeitschrift fur Anorganische und Allgemeine Chemie 646, 842-848 (2020).

39. Browne, W. R. \& McGarvey, J. J. Raman scattering and photophysics in spin-state-labile d6 metal complexes. Coordination Chemistry Reviews 250, 1696-1709 (2006).

40. Stark, C. W. et al. Interligand electron transfer in heteroleptic ruthenium(II) complexes occurs on multiple time scales. Journal of Physical Chemistry A 119, 4813-4824 (2015).

41. Brennaman, M. K. et al. Turning the $[R u(b p y) 2 d p p z] 2+$ light-switch on and off with temperature. Journal of the American Chemical Society 124, 15094-15098 (2002).

42. Hughes, H. P., Martin, D., Bell, S., McGarvey, J. J. \& Vos, J. G. Photophysical and Photochemical Properties of Dinuclear Ruthenium(II) Complexes Containing 2,2'-Bipyridine and 1,10Phenanthroline Moieties. Inorganic Chemistry 32, 4402-4408 (1993).

43. Rau, S. et al. A supramolecular photocatalyst for the production of hydrogen and the selective hydrogenation of tolane. Angewandte Chemie - International Edition 45, 6215-6218 (2006).

44. Mengele, A. K., Kaufhold, S., Streb, C. \& Rau, S. Generation of a stable supramolecular hydrogen evolving photocatalyst by alteration of the catalytic center. Dalton Transactions 45, 6612-6618 (2016).

45. Pfeffer, M. G. et al. Optimization of hydrogen-evolving photochemical molecular devices. Angewandte Chemie - International Edition 54, 6627-6631 (2015).

46. Ozawa, H., Haga, M. A. \& Sakai, K. A photo-hydrogen-evolving molecular device driving visiblelight-induced EDTA-reduction of water into molecular hydrogen. Journal of the American Chemical Society 128, 4926-4927 (2006).

47. Masaoka, S., Mukawa, Y. \& Sakai, K. Frontier orbital engineering of photo-hydrogen-evolving molecular devices: A clear relationship between the $\mathrm{H} 2$-evolving activity and the energy level of the LUMO. Dalton Transactions 39, 5868-5876 (2010).

48. Ozawa, H., Kobayashi, M., Balan, B., Masaoka, S. \& Sakai, K. Photo-hydrogen-evolving molecular catalysts consisting of polypyridyl ruthenium(II) photosensitizers and platinum(II) catalysts: Insights into the reaction mechanism. Chemistry - An Asian Journal 5, 1860-1869 (2010).

49. Ajayakumar, G., Kobayashi, M., Masaoka, S. \& Sakai, K. Light-induced charge separation and photocatalytic hydrogen evolution from water using RullPtIl-based molecular devices: Effects of introducing additional donor and/or acceptor sites. Dalton Transactions 40, 3955-3966 (2011).

50. Suneesh, C. V. et al. Mechanistic studies of photoinduced intramolecular and intermolecular electron transfer processes in RuPt-centred photo-hydrogen-evolving molecular devices.

Physical Chemistry Chemical Physics 16, 1607-1616 (2014). 
51. Miyaji, M., Kitamoto, K., Ozawa, H. \& Sakai, K. Synthesis and Characterization of a RuPt-Based Photo-Hydrogen-Evolving Molecular Device Tethered to a Single Viologen Acceptor. European Journal of Inorganic Chemistry 2017, 1237-1244 (2017).

52. Lo, H. C. et al. Bioorganometallic chemistry. 13. Regioselective reduction of NAD+ models, 1benzylnicotinamde triflate and B-nicotinamide ribose-5'-methyl phosphate, with in situ generated $[\mathrm{Cp} * \mathrm{Rh}(\mathrm{Bpy}) \mathrm{H}]+:$ Structure-activity relationships, kinetics, and mechanistic aspect. Inorganic Chemistry 40, 6705-6716 (2001).

53. Ganesan, V., Sivanesan, D. \& Yoon, S. Correlation between the Structure and Catalytic Activity of [Cp*Rh(Substituted Bipyridine)] Complexes for NADH Regeneration. Inorganic Chemistry 56, 1366-1374 (2017).

54. Zhang, Y. et al. $\mathrm{Cu}(\mathrm{i})$ : Vs. Ru(II) photosensitizers: Elucidation of electron transfer processes within a series of structurally related complexes containing an extended $\pi$-system. Physical Chemistry Chemical Physics 20, 24843-24857 (2018).

55. Kuhnt, C. et al. Investigation of substitution effects on novel ru-dppz complexes by Raman spectroscopy in combination with DFT methods. Journal of Raman Spectroscopy 41, 922-932 (2010).

56. Chen, W., Turro, C., Friedman, L. A., Barton, J. K. \& Turro, N. J. Resonance Raman investigation of $\mathrm{Ru}(\mathrm{phen}) 2(\mathrm{dppz}) 2+$ and related complexes in water and in the presence of DNA. Journal of Physical Chemistry B 101, 6995-7000 (1997).

57. Walsh, P. J., C.gordon, K., Lundin, N. J. \& Blackman, A. G. Photoexcitation in $\mathrm{Cu}(\mathrm{I})$ and $\mathrm{Re}(\mathrm{I})$ complexes containing substituted dipyrido[3,2-a:2', $3^{\prime}$-c]phenazine: A spectroscopic and density functional theoretical study. Journal of Physical Chemistry A 109, 5933-5942 (2005).

58. Zedler, L. et al. Resonance-Raman spectro-electrochemistry of intermediates in molecular artificial photosynthesis of bimetallic complexes. Chemical Communications 50, 5227-5229 (2014).

59. Zhang, Y. et al. In situ spectroelectrochemical and theoretical study on the oxidation of a $4 \mathrm{H}-$ imidazole-ruthenium dye adsorbed on nanocrystalline TiO2 thin film electrodes. Physical Chemistry Chemical Physics 17, 29637-29646 (2015).

60. Zedler, L., Krieck, S., Kupfer, S. \& Dietzek, B. Resonance Raman spectro-electrochemistry to illuminate photo-induced molecular reaction pathways. Molecules 24, 245 (2019).

61. Zedler, L. et al. Redox state sensitive spectroscopy of the model compound [(H-dcbpy) 2Rull(NCS)2]2- (dcbpy = 2,2'-bipyridine-4,4'-dicarboxylato). Journal of Physical Chemistry C 117, 6669-6677 (2013).

62. Schindler, J. et al. Spectroelectrochemical Investigation of the One-Electron Reduction of Nonplanar Nickel(II) Porphyrins. ChemPhysChem 17, 3480-3493 (2016).

63. Zhang, Y., Heberle, M., Wächtler, M., Karnahl, M. \& Dietzek, B. Determination of side products in the photocatalytic generation of hydrogen with copper photosensitizers by resonance Raman spectroelectrochemistry. RSC Advances 6, 105801-105805 (2016).

64. Zedler, L. et al. Trapped in imidazole: How to accumulate multiple photoelectrons on a blackabsorbing ruthenium complex. Chemistry - A European Journal 20, 3793-3799 (2014). 
65. Sun, Y., Liu, Y. \& Turro, C. Ultrafast dynamics of the low-lying 3MLCT states of [Ru(bpy)2(dppp2)]2+. Journal of the American Chemical Society 132, 5594-5595 (2010).

66. Yoshikawa, N. et al. Transition states of the 3MLCT to 3MC conversion in Ru(bpy)2(phen derivative)2+ complexes. Journal of Molecular Structure 1094, 98-108 (2015).

67. Tan, S. S., Yanagisawa, S., Inagaki, K., Kassim, M. B. \& Morikawa, Y. Experimental and computational studies on ruthenium(ii) bis-diimine complexes of $N, N^{\prime}$-chelate ligands: The origin of changes in absorption spectra upon oxidation and reduction. Physical Chemistry Chemical Physics 21, 7973-7988 (2019). 